Relations industrielles

Industrial Relations

\title{
The Tyranny of Work, par James W. Rinehart, Don Mills, Longman Canada Ltd, 1975, 184 p.
}

\section{Gilles Dussault}

Volume 31, numéro 2, 1976

URI : https://id.erudit.org/iderudit/028715ar

DOI : https://doi.org/10.7202/028715ar

Aller au sommaire du numéro

Éditeur(s)

Département des relations industrielles de l'Université Laval

ISSN

0034-379X (imprimé)

1703-8138 (numérique)

Découvrir la revue

Citer ce compte rendu

Dussault, G. (1976). Compte rendu de [The Tyranny of Work, par James W.

Rinehart, Don Mills, Longman Canada Ltd, 1975, 184 p.] Relations industrielles /

Industrial Relations, 31(2), 325-325. https://doi.org/10.7202/028715ar

Tous droits réservés (C) Département des relations industrielles de l'Université Laval, 1976
Ce document est protégé par la loi sur le droit d'auteur. L’utilisation des services d'Érudit (y compris la reproduction) est assujettie à sa politique d'utilisation que vous pouvez consulter en ligne.

https://apropos.erudit.org/fr/usagers/politique-dutilisation/ 
de la gestion des systèmes et de l'évaluation de la performance des systèmes.

Évidemment, ce recueil ne peut servir de lecture de chevet. Il faut s'armer d'un crayon, d'un bout de papier et de beaucoup de patience pour décortiquer chacun des textes et en comprendre l'essentiel. Cependant, un tel recueil permet d'économiser beaucoup de temps dans la recherche de bons articles sur le sujet, puisqu'on les retrouve tous regroupés dans un seul volume.

\section{Université Laval}

\section{Laurent BÉLANGER}

The Tyranny of Work, par James W. Rinehart, Don Mills, Longman Canada Ltd, $1975,184 \mathrm{p}$

Le thème du travail aliénant a donné lieu, depuis Marx, à une littérature abondante. Le contenu du concept d'aliénation a aussi considérablement évolué depuis que Marx l'a utilisé pour désigner la dépossession du travailleur industriel de ses moyens de production et du fruit de son travail. A ces formes d'aliénation, le taylorisme en a ajouté d'autres en vidant les tâches industrielles de leur substance. Les travaux du sociologue Georges Friedman et les écrits du syndicaliste Hyacinthe Dubreuil vers la fin des années cinquante ont largement contribué à mettre en lumière les conséquences néfastes du modèle de travail taylorien: travail répétitif, monotone, sans signification, qui ne nécessite pas de qualification particulière, qui ne fait pas appel à l'intelligence de celui qui l'exécute, travail aliénant, en somme.

C'est un peu l'histoire de l'aliénation du travail que James Rinehart fait dans ce petit essai au titre percutant. Pour lui, on peut parler de l'aliénation comme d'une condition "in which individuals have little or no control over (a) The purposes and products of the labour process, (b) The overall organization of the workplace, and (c) The immediate work process itself". (p. 17). Le travail aliénant va de pair, selon lui, avec le capitalisme économique qui implique (1) une concentration des moyens de production dans les mains d'un nombre restreint d'individus, (2) une économie de marché où le profit détermine les moyens et les fins de la production et (3) une division du travail très poussée.

Cette forme d'aliénation a traditionnellement été considérée comme propre au travail industriel: d'ailleurs, on considère habituellement des réactions ouvriè- res comme les grèves sauvages, les sabotages, le freinage, etc... comme autant de façon de répudier un travail vidé de son sens. Rinehart montre que si le travail en usine est manifestement aliénant, le travail des cols blancs ne présente pas moins tous les symptômes de l'aliénation. Il interprète les grèves des employés des secteurs public et parapublic (celle de Québec, en 1972, en particulier) comme étant, en partie, des réactions contre un travail de plus en plus bureaucratisé. Même les administrateurs, qui se sentent perdus dans des hiérarchies toujours plus complexes, commencent à connaître l'aliénation du travail.

Existe-t-il des façons de contrer l'aliénation du travail moderne? L'auteur examine, quant à lui, cint possibilités de solution: (1) l'accroissement du temps consacré au loisir, comme forme de compensation. Cette solution est illusoire selon lui: plusieurs études ont démontré que l'individu aliéné au travail avait tendance à se comporter de façon aliénée dans ses loisirs également (consommation pure et simple de loisirs, attitudes de spectateur, etc...). (2) L'automation des tâches les plus aliénantes ne représente qu'une solution à très long terme. (3) L'humanisation des tâches par leur enrichissement ou par l'amélioration des relations humaines dans l'entreprise n'est une solution qui ne profite, en définitive, qu'au management: les structures d'autorité traditionnelles ne sont pas fondamentalement modifiées par des techniques du genre de celles du «job enrichment ». (4) Le syndicalisme qui pourrait apparaître comme un excellent moyen d'améliorer les conditions de travail n'a pas su, selon Rinehart, jouer son rôle en ces matières. Les syndicats se sont la plupart du temps contentés de monnayer de mauvaises conditions de travail et, par leur insistance à étendre la portée des accords collectifs de travail, ils contribuent à multiplier les obstacles à une véritable modification des tâches. (5) Enfin, il y a le contrôle ouvrier, l'autogestion, qui apparaît à l'auteur comme la seule voie pouvant permettre aux individus de se donner les véritables moyens de redonner un sens à leur travail. De nombreuses expériences de ce type sont en cours, dont les plus connues au Québec sont celles de Tricofil et de Tembec; il faudra suivre leur évolution pour voir dans quelle mesure l'autogestion permet d'annuler les effets les plus pénibles de l'organisation capitaliste du travail.

Université Laval

\section{Gilles DUSSAULT}

